\section{Newton in Japan}

\section{Translators of scientific texts add their own, cultural interpretations.}

\section{Scott L. Montgomery}

saac Newton wrote in Latin and in English. Today his works, and the vocabulary they introduced, are found in every major language of the world. Are all these versions of the 'founder of modern physics', roaming the shelves and classrooms of the planet, essentially the same? Is the terminology of 'force', 'velocity' and 'acceleration', for all practical purposes, identical in tongues otherwise as different as English and Japanese?

The story of Newton's entry into Japanese is an interesting one. The man responsible for this epochal feat was Shizuki Tadao, a rangaku-sha (scholar of Dutch studies), who, between 1798 and 1802, composed a work of three volumes in which Newtonian physics and astronomy formed an essential core. The title of this work is revealing: Rekishô Shinsho, "New Writings on Calendrical Phenomena", indicating allegiance to the traditional focus of astronomy in Japan, which had been guided by Chinese neoConfucian natural philosophy for centuries. But Shizuki's title was also something of a screen, behind which lay a revolutionary set of introductions that would help overturn neo-Confucian science even while incorporating portions of it.

Shizuki composed his work at a crucial moment in the history of Japanese science. From 1630 to 1720 , no Western books had been allowed to enter the country, and exchange with Europe was restricted to trading with the Dutch, who continued as the sole supplier of things Western up until the nineteenth century. Only after about 1770 did scientific books become a significant part of this exchange. These were handled, and either partly or wholly translated, by the rangaku-sha, who were employees of the government. The Tokugawa shogunate remained suspicious of Western texts, and especially condemned any reference to religious matters or the word "God" (thus making scientific books the safest to trade). But by the 1790s, when Shizuki was active, a few translations of European medical and astronomical works had finally been published and made available, allowing scholars access to new styles of explanation, drawing, and prediction. A burgeoning interest in European science resulted among Japanese intellectuals.

The larger situation was thus uncertain. Shizuki would have been ill-advised to use the real name of his principal source: Inleidinge tot de Waare Natuuren Sterrekunde-
"Introduction to the True Natural Philosophy and Astronomy". This was itself a Dutch translation from an original popular-science book by the English author John Keill, one of Newton's most ardent promoters. But what did Shizuki do with it?

In Western terms, Shizuki might be called both an 'ancient' and a 'modern'. As an official interpreter and a scholar of the Chinese classics (as nearly all scholars were), he felt the need to interpret the heliocentric view in accord with the ethical prerogatives of neoConfucianism, to whit: "There exists a governing centre in all things: for an individual, the heart; for a household, the father; for a province, the government; for the whole

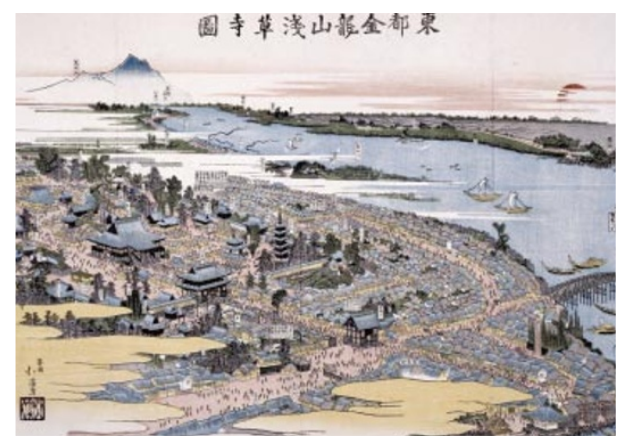
图寺草清山称全都果 country, the imperial court; and for the entire universe, the Sun." Thus could a Suncentred cosmos be made acceptable.

What of his translations of newtonian terms? Here Shizuki showed himself a modern thinker of great ingenuity. For many basic words - force, gravity, velocity, elasticity, attraction — he employed a simple system. This involved using the ideogram for a related action in each case - movement, weight, speed, stretch, pull - and combining it with the ideogram for strength or power (chikara). Thus force became 'movement power' (power to create movement); gravity was 'weight power', velocity 'speed power', and so forth. Each term thus gained a concrete sensibility, a link to everyday experience, and also a degree of self-explanation largely lacking in the English or Latin. For other terms, Shizuki returned to the neoConfucian influence: vacuum rendered as shink $\hat{u}$, 'true emptiness'; corpuscle as bunshi, 'child part' (which later became the term for molecule); centripetal and centrifugal, as kyûshin and enshin, meaning 'seeking the heart' and 'receding from the heart'.

All these terms remain in use today, as part of the basic vocabulary of modern physics. Indeed, later translations of Newton's own books were forced to obey Shizuki's choices, so widely had they been adopted. Moreover, they set patterns that were followed in coining new terminology in the nineteenth and twentieth centuries. Newtonian language thus condenses a moment when loyalties to both China and the West were in motion. To the knowing eye or ear,

\section{督淺山樶金都東}

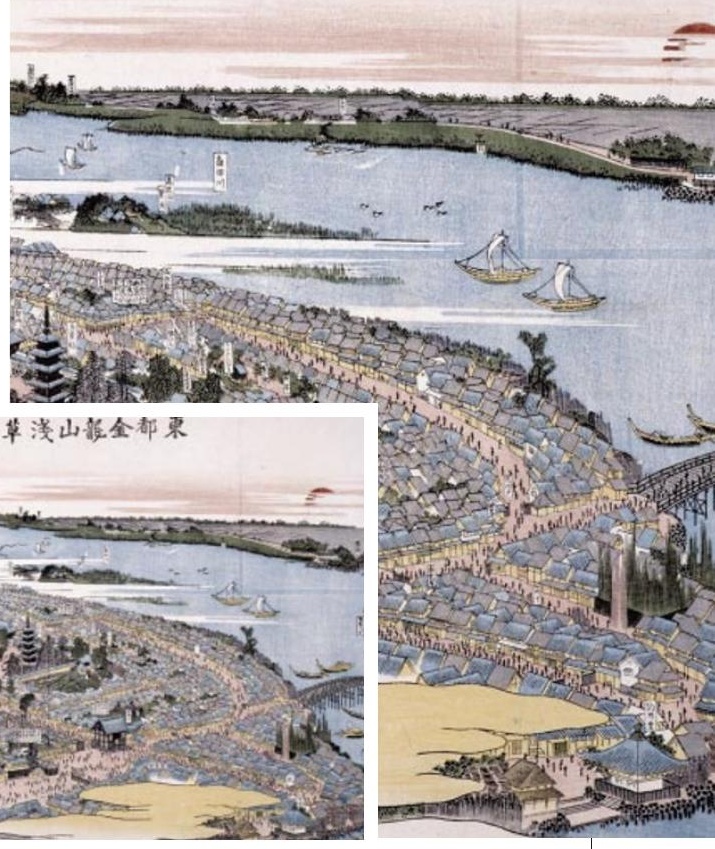

Ancient city, new ideas: Tokyo in Shizuki's time.

the daily use of this language today rehearses such a moment.

For most of the eighteenth century and well into the early nineteenth, translation was the dominant work performed by people involved in Japanese science. 'Scientists' we may call them, but they were translators first, and because of this, their influence was profound. The creation of a new vocabulary in science is no mean feat. To a degree, Shizuki Tadao deserves a place beside Lavoisier, Linnaeus and their peers.

How, then, to answer our initial question? Is Newton's terminology the same in all languages? The case presented here suggests that there are, in fact, a host of 'Newtons' roaming the globe today - that newtonian language has been adapted significantly to each new linguistic context, not the other way around. Can this be said to challenge the paternity of this great 'father' of modern physics? Only if we demand that such an image must be absolute, that it must erase all those workers who made newtonian thought a living thing in other languages. For Newton is today much larger and more polymorphic than he was in the past. The Japanese example teaches us that his intellectual parenthood is as much a matter of what the world has done with his legacy as of its original content.

Scott L. Montgomery is a geologist and independent scholar. His most recent books include Science in Translation (University of Chicago Press, 2000). e-mail:scott.montgomery@prodigy.net 